\title{
Nicotine induced gastric injury. A quantitative macroscopic and microscopic analysis of the protective effects of sucralfate and feeding
}

\author{
W M Hui, H Joana, B W Chen, C H Cho, C T Luk, S K Lam
}

\begin{abstract}
Nicotine, while an important component of cigarettes, does not cause gross gastric mucosal damage, although its microscopic effect remains unknown. We have evaluated the histology and the microvascular permeability of (a) the effect of nicotine alone or in combination with ethanol on the gastric mucosa of rats and (b) the effect of feeding and sucralfate on the mucosa of rats treated with nicotine and ethanol. Mucosal injury was assessed histologically by the depth of injury and microvascular permeability by the leakage of fluorescein isothiocyanate-labelled albumin. Our results show that nicotine induced microscopic mucosal damage and accentuated the damage induced by alcohol. The damaging effects on mucosa of nicotine and ethanol, alone or in combination, were reduced by pretreatment with sucralfate. Similarly, feeding reduced the degree of mucosal injury. Nicotine and ethanol increased leakage of albumin into the interstitium and the leakage was reduced after sucralfate pretreatment. This study substantiates the adverse effect of smoking on mucosal damage. Vascular factors are probably involved in the pathogenesis.
\end{abstract}

While cigarette smoking is strongly associated with peptic ulcer disease, ${ }^{12}$ the pathogenetic role of cigarettes is unknown. Nicotine, an important component of cigarettes, has been shown to increase parietal cell mass and peak acid output. ${ }^{3}$ Chronic nicotine administration has been shown to worsen ethanol induced gastric mucosal injury macroscopically in rats but by itself does not cause mucosal ulceration. ${ }^{45}$ It is not known,

TABLE I Experimental protocol for the study of macroscopic and microscopic injury of gastric mucosa

Departments of Medicine, Pathology, and Pharmacology, University of Hong Kong, Queen Mary Hospital, Hong Kong

W M Hui

H Joana

B W Chen

$\mathrm{C}$ H Cho

CT Luk

S K Lam

Correspondence to:

Professor S K Lam,

University Department of

Medicine, Queen Mary

Hospital, Hong Kong.

Accepted for publication 14 June 1990

Fasted rats:

No pretreatment with nicotine

1. $1.5 \mathrm{ml} 0.25 \%$ methylcellulose $+1.5 \mathrm{ml}$ deionised water

2. $1.5 \mathrm{ml} 0.25 \%$ methylcellulose $+1.5 \mathrm{ml}$ ethanol

3. Sucralfate $100 \mathrm{mg}$ in $1.5 \mathrm{ml} 0.25 \%$ methylcellulose $+1.5 \mathrm{ml}$ ethanol

4. Sucralfate $200 \mathrm{mg}$ in $1.5 \mathrm{ml} 0.25 \%$ methylcellulose $+1.5 \mathrm{ml}$ ethanol

Pretreatment with nicotine:

2. $1.5 \mathrm{ml} 0.25 \%$ methylcellulose $+1.5 \mathrm{ml}$ ethanol

3. Sucralfate $100 \mathrm{mg}$ in $1.5 \mathrm{ml} 0.25 \%$ methylcellulose $+1.5 \mathrm{ml}$ ethanol

4. Sucralfate $200 \mathrm{mg}$ in $1.5 \mathrm{ml} 0.25 \%$ methylcellulose $+1.5 \mathrm{ml}$ ethanol

Fed rats without pretreatment with nicotine:

1. $1.5 \mathrm{ml} 0 \cdot 25 \%$ methylcellulose $+1.5 \mathrm{ml}$ ethanol

2. Sucralfate $100 \mathrm{mg}$ in $1.5 \mathrm{ml} 0.25 \%$ methylcellulose $+1.5 \mathrm{ml}$ ethanol

3. Sucralfate $200 \mathrm{mg}$ in $1.5 \mathrm{ml} 0.25 \%$ methylcellulose $+1.5 \mathrm{ml}$ ethanol however, whether nicotine can induce microscopic injury. Sucralfate, a site protective agent, protects the gastric mucosa against ethanol induced necrosis and increases gastric mucosal blood flow in rats. ${ }^{67}$ It binds to the base of peptic ulcers selectively ${ }^{8}$ and protects the gastric mucosa from pepsin, acid, and bile. ${ }^{9}$ It is not known whether sucralfate protects the gastric mucosa against nicotine and ethanol induced gastric mucosal injury. The present study was undertaken to assess the effect of nicotine and feeding on the gross appearance, histology, and microvascular permeability of gastric mucosa and whether sucralfate has any protective effect against nicotine induced gastric mucosal injury.

\section{Methods}

Male Sprague-Dawley rats weighing 150-200 g were used for the study. They were housed in an air-conditioned room with the temperature kept at $22 \pm 2^{\circ} \mathrm{C}$ and humidity at $65-70 \%$ and were fed a standard pellet diet (Ralston Purina Co, North Carolina, USA). They were anaesthetised by pentobarbitone (Abbott) $50 \mathrm{mg} / \mathrm{kg}$ given intraperitoneally. A gastric chamber preparation was made, which has been described in detail previously. ${ }^{10}$ Sucralfate $100 \mathrm{mg}$ and $200 \mathrm{mg}$ suspended in $1.5 \mathrm{ml} 0.25 \%$ methylcellulose as control was added to the chambers of groups of six to eight rats. Methylcellulose was used as the base because sucralfate forms a more stable and homogeneous suspension with methylcellulose than with deionised water. Fifteen minutes later $1.5 \mathrm{ml} 100 \%$ ethanol or deionised water was added to the chamber. The rats were sacrified 45 minutes after the addition of alcohol or control substance, and the stomach was resected en bloc, unfolded, and fixed in $0.5 \%$ formalin. The experiments were performed in rats fasted and fed, with and without pretreatment with nicotine (Table I). Rats were fasted for 24 hours or fed ad libitum until they were anaesthetised.

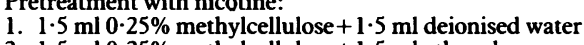

The rats were allowed to drink nicotine bitartrate $25 \mu \mathrm{g} / \mathrm{ml}$ of tap water for 10 days (mean (SD) $39 \cdot 3(2 \cdot 5) \mathrm{ml}$ per day) before the gastric chamber preparation was made.

\section{ASSESSMENT OF MACROSCOPIC DAMAGE}

The stomachs were examined macroscopically for ulceration. An ulcer index was obtained from the areas of the ulceration traced on a transparency and projected onto graph paper with $1 \mathrm{~mm} \times 1 \mathrm{~mm}$ squares.
NICOTINE PREPARATION 


\section{HISTOLOGICAL ASSESSMENT}

From the glandular part of the stomach two square pieces of approximately $8 \mathrm{~mm} \times 8 \mathrm{~mm}$ were cut from the greater curvature of the stomach. Two tissue blocks were taken from the necrotic areas and another two blocks from the non-necrotic areas from each piece of the stomach, making a total of eight blocks for each rat. Samples and blocks were taken from the same region of the stomach of each rat to ensure that they were comparable. The blocks of tissue were fixed, dehydrated, and mounted on paraffin blocks, and longitudinal sections of $0.25 \mu \mathrm{m}$ or less were cut. These were examined after staining with haematoxylin and eosin. As the blocks were cut as uniformly as possible, the span of the tissue sampled from the necrotic and nonnecrotic areas was nearly constant (approximately $11 \mathrm{~mm}$ ). The slides were assessed blind by the pathologists who were unaware of the treatments given to the rats.

\section{MICROSCOPIC ANALYSIS}

The severity of damage was graded according to the depth of tissue damage and these criteria have been reported by Lacy and Ito." Briefly, the damage was graded as follows: (a) Grade 0 all gastric mucosal cells appeared intact and had normal shape, location, appearance, and density. Surface mucous cells were columnar to cuboidal with varying amounts of apical mucous granules. Gastric pits were of expected depth and the gastric glands contained intact mucous neck, parietal, chief, and endocrine cells. (b) Grade I surface mucous cells on the luminal free surface were vacuolated, had pyknotic nuclei, lightly stained cytoplasm, or lysed cytoplasm. Some cell exfoliation was present. Gastric pit cells were undamaged. (c) Grade II - in addition to extensive luminal surface cell damage the cells lining the gastric pits were also disrupted and exfoliated. The gastric gland cells were damaged. (d) Grade III - beneath the damaged surface and gastric pits cellular damage was evident in the gastric glands. Parietal cells with lucent cytoplasm were common. Many exfoliated cells and whole layers of necrotic superficial epithelium were also present. The lamina propria was often seen in direct continuity with the stomach lumen.

To determine the extent and degree of mucosal injury, the span of the sections with

TABLE II Effect of sucralfate after nicotine and ethanol treatment on vascular permeability measured by the degree of leakage of fluorescein isothiocyanate-albumin

\begin{tabular}{ll}
\hline Rat preparation & Degree of leakage \\
\hline Fasted rats: & 0 \\
Methylcellulose alone & 3 \\
Ethanol alone & $1-2$ \\
Nicotine alone & 3 \\
Nicotine+ethanol & 1 \\
Sucralfate $100 \mathrm{mg}+$ ethanol & $1-2$ \\
Sucralfate $100 \mathrm{mg}+$ nicotine +ethanol & $0-1$ \\
Sucralfate $200 \mathrm{mg}+$ ethanol & 1 \\
Sucralfate $200 \mathrm{mg}+$ ethanol + nicotine & \\
Fed rats: & 0 \\
Methylcellulose alone & 3 \\
Ethanol alone & 2 \\
Nicotine alone & \\
\hline$\star 0=$ none; $1=$ mild; $2=$ moderate; $3=$ severe &
\end{tabular}

$\star 0=$ none; $1=$ mild $; 2=$ moderate; $3=$ severe . each degree of injury was measured with an ocular micrometer (Nikon, Japan). For each rat the following data were obtained: (i) the span of the gastric mucosa of the sections from each of the tissue blocks of each stomach and (ii) the percentage of the mucosal span with each degree of injury. From the necrotic area histology was performed to confirm the span microscopically equivalent to necrotic lesions. Comparisons were made between the data for each group of six to eight rats, each with four tissue blocks sampled from the non-necrotic areas and four from the necrotic area.

FLUORESCEIN ISOTHIOCYANATE-ALBUMIN STUDY Fluorescein isothiocyanate-labelled albumin was used to assess macromolecular permeability. ${ }^{1+} \mathrm{A}$ dose of $250 \mathrm{mg} / \mathrm{kg}$ was given intravenously and 30 minutes later the active drug or Sorensen's phosphate buffer $\mathrm{pH} 7 \cdot 4$ was added to the chamber of the ex vivo system followed by the same sequence as for the histological study. The animal was sacrified and the stomach fixed in neutral phosphate buffered formalin. Each experiment was performed on three rats. The tissue was sectioned after embedding in paraffin and examined by fluorescence microscopy for leakage of fluorescein into the interstitium and graded from $0-3$, according to the degree of leakage. The experiments were performed in fasted rats and fed rats with methylcellulose, ethanol, or nicotine alone (see Table II).

\section{STATISTICAL COMPARISON}

Comparisons between groups were done by analysis of variance, using the Duncan procedure of multiple comparison to avoid overoptimistic results obtained by using the multiple $t$ test. $^{1213}$ The results were expressed as mean (SD).

\section{Results}

SPAN OF MUCOSA ASSESSED

The mean span of the mucosa assessed varied from $10.6 \mathrm{~mm}$ to $11.3 \mathrm{~mm}$ in the groups of rats studied and there was no significant difference between the various groups.

\section{ASSESSMENT OF THE NECROTIC AREAS}

Microscopically, over $98 \%$ of the span of the mucosa was confirmed as necrotic lesions. Therefore, only macroscopic assessment and a comparison of areas of ulceration (ulcer index) were made.

\section{EFFECT OF ETHANOL}

Neither macroscopic nor microscopic damage was detected in the control rats treated with methylcellulose. After the addition of ethanol both macroscopic injury (mean (SD) ulcer index $46 \cdot 4(7 \cdot 1) \mathrm{mm}^{2}$ ) and microscopic injury were detected (percentage mucosal injury: grade $\mathrm{I}=16(4 \cdot 4) \%$, grade II $=32(4 \cdot 1) \%$, grade III $=40$ $(4 \cdot 1) \%)$. 


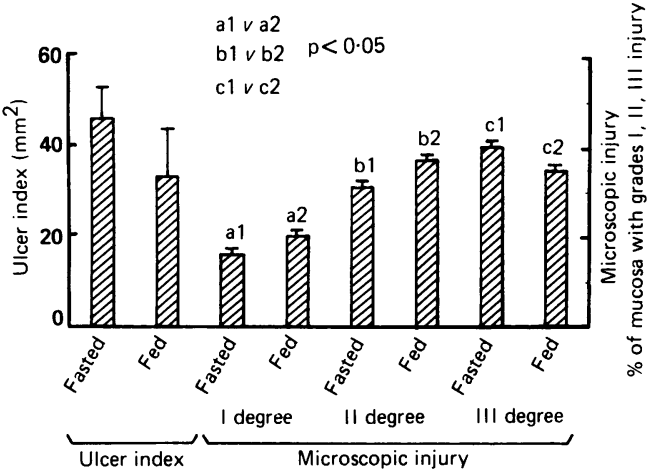

Figure 1: Ethanol induced macroscopic injury (ulcer index) and different degrees of microscopic injury in fasted and fed rats. Grade III injury was significantly higher in fasted than in fed rats $(p<0.05)$.

\section{EFFECT OF FEEDING}

The mean ulcer index was higher in fasted than in fed rats but the difference was not significant (Fig 1). Microscopically, the percentage of mucosa with grade III injury was significantly higher in fasted than in fed rats $(p<0.05)$. For grade I and II injuries, however, the percentage was significantly lower in fasted than in fed rats $(\mathrm{p}<0.05)$ (Fig 1).

\section{EFFECT OF NICOTINE}

Macroscopically, no ulcer was detected in rats treated with nicotine alone. Pretreatment with nicotine resulted in a significantly higher ulcer index with subsequent ethanol treatment $(\mathrm{p}<0.05$, Fig 2$)$.

Microscopically, treatment with nicotine alone resulted in a significant increase in grade I to III mucosal injury when compared to control $(\mathrm{p}<0.05)$ (Fig 3). With subsequent ethanol treatment, however, there was no difference in the percentage of the mucosa with grade III injury whether the rats had received nicotine treatment or not (Fig 4), as ethanol alone had already produced appreciable mucosal damage. Similar findings were observed with grade I and II mucosal injuries (data not shown).

EFFECT OF SUCRALFATE

The ulcer index was significantly lower with

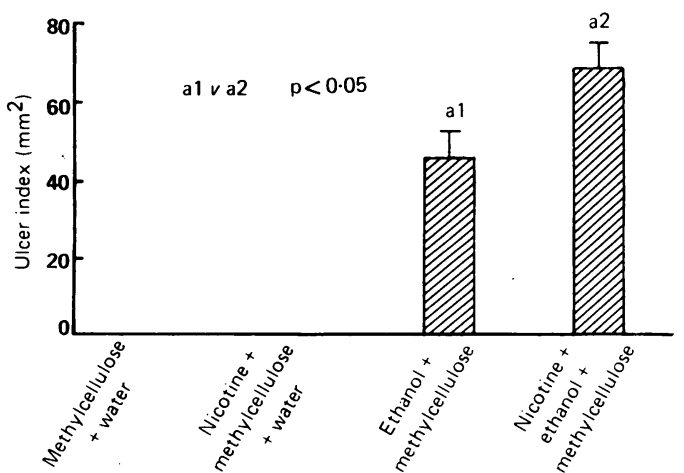

Figure 2: Ulcer index of rats treated with ethanol with and without pretreatment with nicotine. No macroscopic ulcer was observed in control (methylcellulose) or nicotine treated rats. Pretreatment with nicotine resulted in a significantly higher ulcer index with subsequent ethanol treatment.

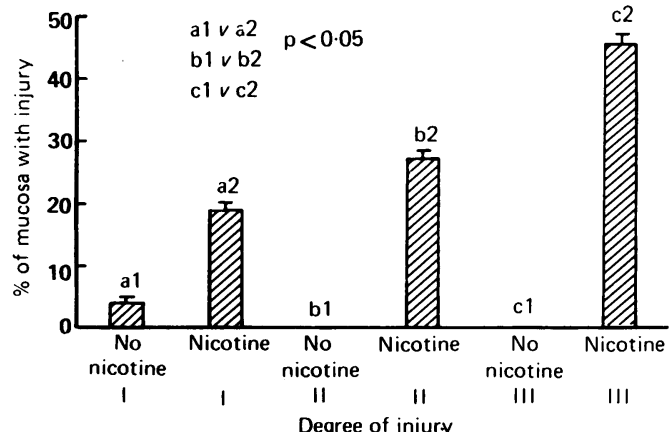

Figure 3: Microscopic injury induced by nicotine. Rats treated with nicotine had a significantly higher percentage of mucosa with grades I, II, and III injury.

sucralfate $100 \mathrm{mg}$ and $200 \mathrm{mg}$ than control (methylcellulose alone) in ethanol treated rats irrespective of whether they had been pretreated with nicotine or not (both $\mathrm{p}<0.05$ ) (Fig 4).

Microscopically, the percentage of mucosa with grade III damage was significantly lower after treatment with sucralfate $100 \mathrm{mg}$ or $200 \mathrm{mg}$ in ethanol treated rats with or without pretreatment with nicotine $(p<0.05)$ (Fig 5). In rats treated with both ethanol and nicotine, grade I injury was significantly higher in rats treated with sucralfate $100 \mathrm{mg}$ and $200 \mathrm{mg}$ than the control (methylcellulose), indicating that sucralfate reduced injury to a less severe grade $(p<0.05)$ (Fig 6). In rats treated with ethanol alone there was no significant difference in grade I and II injuries between rats treated with sucralfate $100 \mathrm{mg}$ and $200 \mathrm{mg}$ and the control.

COMPARISON OF THE EFFECT OF SUCRALFATE WITH FEEDING

In ethanol treated rats the ulcer index was significantly lower in fasted rats given sucralfate $200 \mathrm{mg}$, but not $100 \mathrm{mg}$, than in fed rats $(\mathrm{p}<0.05)$. Microscopically, in ethanol treated rats the percentage of the mucosa with grade III injury was significantly lower in fasted rats given sucralfate $200 \mathrm{mg}$ or $100 \mathrm{mg}$ than in fed rats $(\mathrm{p}<0.05)$ (data not shown).

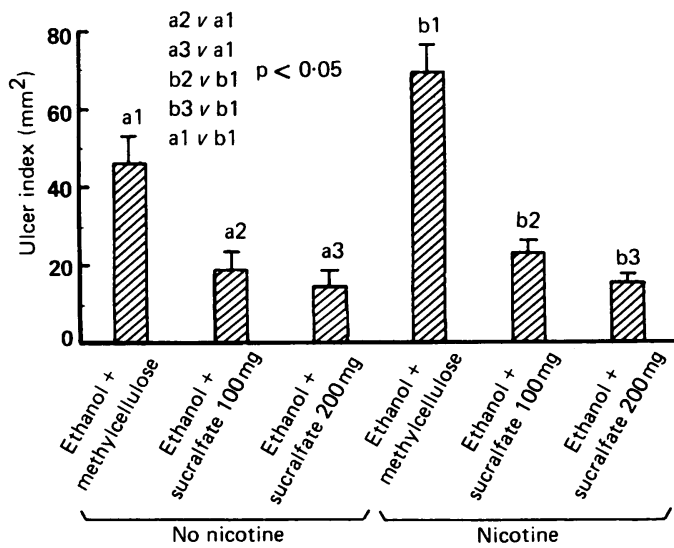

Figure 4: Effect of sucralfate on ulcer index induced by ethanol in rats with or without pretreatment with nicotine. In both groups the ulcer indices were significantly lower after the addition of sucralfate $100 \mathrm{mg}$ or $200 \mathrm{mg}$ when compared with control (all with $p<0.05)$. 


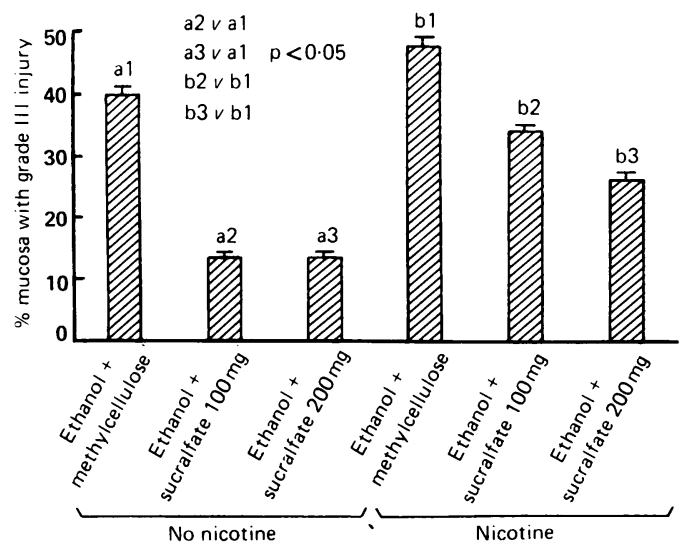

Figure 5: Effect of sucralfate on grade III injury in rats given ethanol with and without pretreatment with nicotine. In both groups mucosal injury was significantly lower after the addition of sucralfate $100 \mathrm{mg}$ or $200 \mathrm{mg}$ compared with control $($ all $p<0 \cdot 05)$.

FLUORESCEIN ISOTHIOCYANATE-ALBUMIN

The results of using fluorescein isothiocyanatealbumin are shown in Table II. Vascular leakage was greater in nicotine treated rats than in control rats. When sucralfate $100 \mathrm{mg}$ was added to rats treated with either ethanol or nicotine and ethanol combined vascular leakage was reduced from grade 3 to grade 1 , and with sucralfate $200 \mathrm{mg}$ this was reduced to grade 0 (Fig 7). There was no difference in vascular leakage between the fasted and fed rats given methylcellulose, ethanol, or nicotine alone.

\section{Discussion}

The present study confirms our previous observation $^{45}$ that nicotine aggravates macroscopic injury induced by ethanol, though nicotine alone does not produce macroscopic damage. Furthermore, the study also shows that nicotine induces microscopic gastric mucosal injury, thus explaining why nicotine aggravates mucosal injury induced by alcohol. The pathogenetic mechanisms are not understood. Short term administration of nicotine is known to increase gastric acid secretion $^{15}$ but when given at the dose and duration used in this study it does not affect

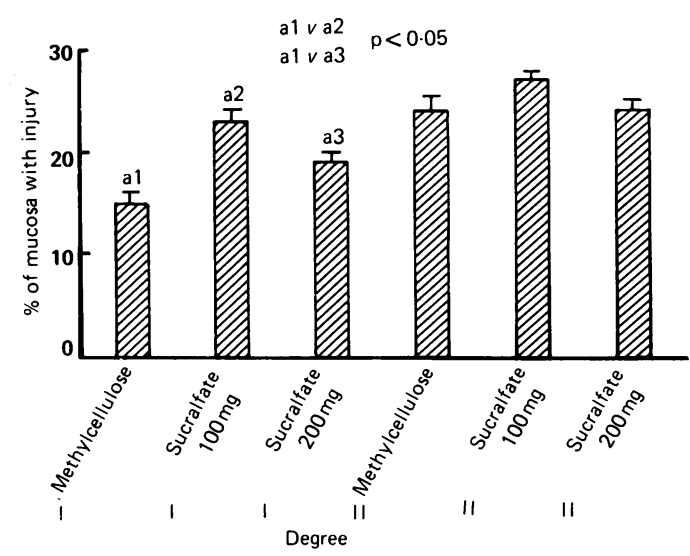

Figure 6: Effect of sucralfate on grades I and II microscopic injury in rats given ethanol and nicotine in combination. Grade I injury was significantly higher after the addition of sucralfate $100 \mathrm{mg}$ and $200 \mathrm{mg}$ compared with control $(p<0.05)$. This, coupled with the reduction of grade III injury (as shown in Fig 5), indicates that sucralfate reduces mucosal injury to a less severe grade.
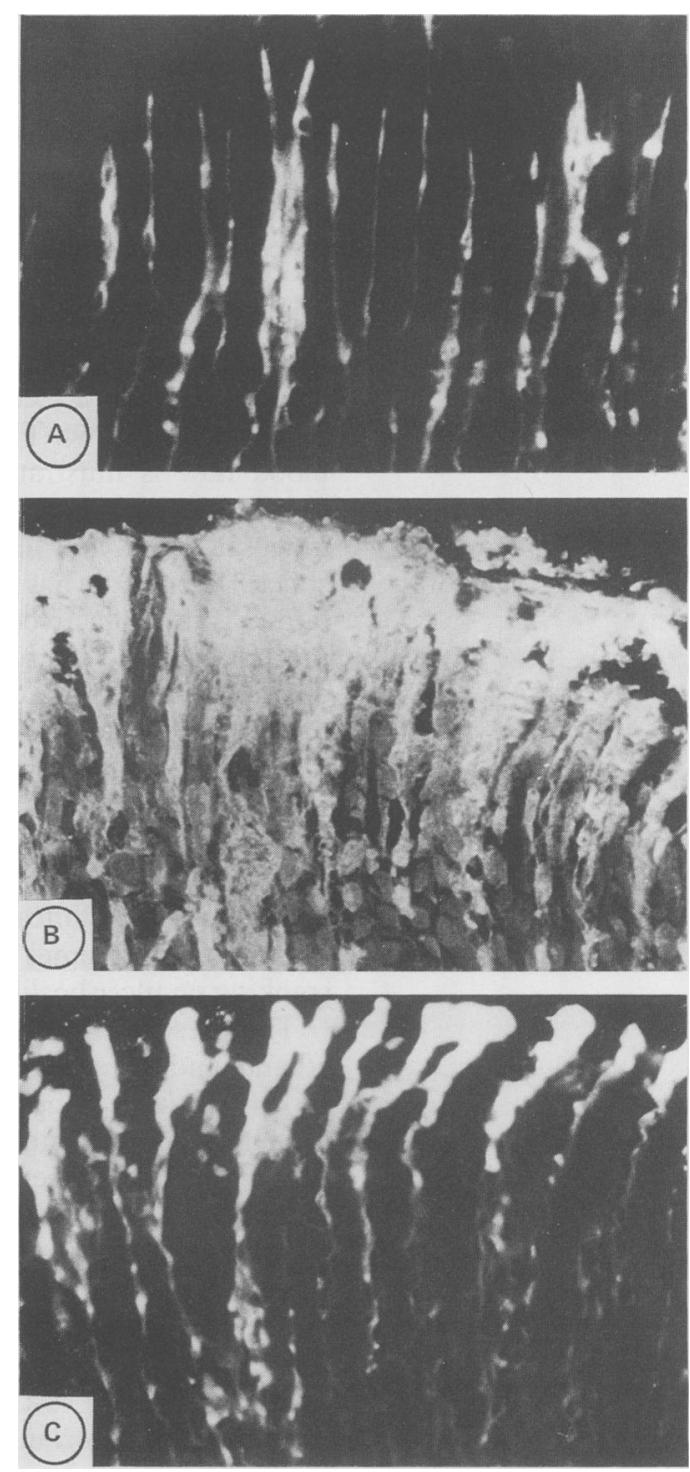

Figure 7: Fluorescence micrograph of longitudinal section of the gastric mucosa after administration of intravenous fluorescein isothiocy anate-albumin intravenously in $(A)$ control rats with the addition of Sorenson's buffer, showing no leakage into the interstitium; in $(B)$ rats treated with alcohol, showing the leakage of fluorescence into the interstitium; $(C)$ after the addition of sucralfate leakage was significantly decreased.

gastric acid secretion. ${ }^{16}$ At the dose used it has been shown to exert a depolarising blocking effect and produce ganglion blockade at the coeliac ganglion. ${ }^{15} 17$ Though the resulting adverse effects of this blockade are uncertain, it is well known that the nerve supply affects gastric mucosal blood flow, ${ }^{18}$ which is thought to be essential in the gastric mucosal defence. ${ }^{19}$ Furthermore, the study has shown that vascular permeability increased after treatment with nicotine alone. It is possible that vascular factors play a part in nicotine induced damage. In this experiment rats were given nicotine $(25 \mu \mathrm{g} / \mathrm{ml})$ in doses simulating the daily intake of a heavy cigarette smoker. ${ }^{20}$ Our results showed that exposure to this dose of nicotine for nine days resulted in microscopic injury. This is reflected clinically by smokers with duodenal ulcers having higher relapse rates ${ }^{21}$ and lower healing rates for ulcers ${ }^{22}$ compared with the nonsmokers.

The effect of feeding on mucosal protection is 
of interest. We showed previously that feeding lessened the fall in gastric mucosal blood flow but the ulcer index was not significantly different between the fasted and fed rats. ${ }^{6}$ This was confirmed in the present experiment. On microscopic analysis, however, the percentage of deep mucosal injury (grade III) was significantly lower in the fed rats, indicating that feeding does protect the mucosa from damage by ethanol. The mechanism for this is unknown but may be related to effect of feeding on increasing gastric mucosal blood flow. The importance of mucosal blood flow is illustrated by the association of gastric mucosal damage with decreased gastric mucosal blood flow induced by haemorrhagic shock. ${ }^{19}$ The study has further shown that sucralfate, a site protective antiulcer agent, reduces macroscopic and microscopic injury induced by ethanol and nicotine either alone or in combination. The protective effect of sucralfate against damage by ethanol was significantly better than the effect of feeding. As noted before, the dose of nicotine given in the present experiment is similar to the amount taken by a heavy smoker. ${ }^{2021}$ This correlates clinically with the finding that sucralfate overcomes the adverse effect of smoking on ulcer healing. ${ }^{22}$

The present experiment also shows that both ethanol and nicotine induced vascular injury, as shown by the leakage of the fluorescein isothiocyanate-albumin into the interstitium. This supports a pathogenetic role of vascular factors in mediating tissue damage. ${ }^{23}$ Sucralfate has been shown to increase gastric mucosal blood flow in a dose-dependent manner. ${ }^{6}$ The fact that sucralfate reduced leakage into the interstitium indicates that the mucosal protective effect may be mediated through vascular protection. This also supports the importance of mucosal blood flow in maintaining the integrity of the mucosa. Feeding in the present experiment did not protect against the vascular injury.

We have shown that nicotine induces microscopic mucosal and vascular damage and that sucralfate protects the mucosa against this damage. Feeding protects the mucosa from ethanol induced gastric damage both macroscopically and microscopically. These results also substantiate the adverse effect of smoking on mucosal integrity and suggest that vascular factors play a part in its pathogenesis.

We are grateful for the secretarial assistance of Miss Mary Chan and Karen Chan. This study was supported by Peptic Ulcer Research Fund (311/041/0372) of the University of Hong Kong.
BWC is visiting professor from lst Teaching Hospital, University of Beijing, Beijing, China.

1 Harrison AR, Elashoff JD, Grossman MI. Cigarette smoking and ulcer disease. In: Smoking and health. $A$ report of the surgeon general. Washington DC: Department of Health, Education and Welfare 1979: 9.3-9.21. (DHEW publication No 79-50066.)

2 Doll R, Jones FA, Pygott F. Effect of smoking on the production and maintenance of gastric and duodenal ulcers. production and mainten
Lancet $1958 ;$ i: $657-62$.

3 Guo FN, Chen GZ, Liu SQ, You YH, Yuan SZ. The effects of smoking and nicotine on the parietal cell mass of human beings and rats. Fournal of Gastroenterology and Hepatology 1986; 1: 45-54.

4 Wong SH, Ogle CW, Cho $\mathrm{CH}$. The influence of chronic or acute nicotine pretreatment on ethanol-induced gastric ulceration in the rat. F Pharm Pharmacol 1985; 38: 537-40.

5 Ogle CW, Cho CH, Wong SH. The effect of nicotine on ethanol-induced gastric ulcers in rats. Experientia 1985; 41: 1140-1.

6 Hui WM, Chen BW, Cho CH, Ng MMT, Lam SK, Luk CT. Sucralfate increases gastric mucosal blood flow in rats. Gut 1989; 30: $1544-51$.

7 Nagashima R, Hoshino E, Hinohara Y, Sakai K, Hata S, Nakano H. Effect of sucralfate on ethanol induced gastric mucosal damage in rat. Scand $\mathcal{F}$ Gastroenterol [Suppl] 1983; 18: 17-20.

8 Nakazawa $S$, Nagashima R, Samloff IM. Selective binding of sucralfate to gastric ulcer in man. Dig Dis Sci 1981; 26: 297-300

9 Schenkein JP, Liu HL, Watkin JB, Shiau JF. Bile salt binding properties of maalox, sucralfate and cholestyramine. Gastroenterology 1983;84: 1300 .

10 Mersereau WA, Hinchey EJ. Effect of gastric acidity on gastric mucosal ulceration induced by hemorrhage in the rat, utilizing a gastric chamber technique. Gastroenterology 1973 64: $1130-5$.

11 Lacy ER, Ito S. Microscopic analysis of ethanol damage to rat gastric mucosa after treatment with a prostaglandin. Gastroenterology 1982; 83: 619-25.

12 Fleiss JL. Statistical methods for rates proportions. New York: Wiley, 1973.

13 Nie NH, ed. SPSS-X, user's guide. New York: McGraw-Hill, 1983 .

14 O'Brien P, Schultz C, Gannon B, Browning J. Protective effects of the synthetic prostaglandin enprostil on the gastric microvasculature after ethanol injury in the rat. $A m \mathcal{F} \mathrm{Med}$ 1986; 81 (suppl 2A): 12-7.

15 Albinus $M$, Frisch G, Klein S. The effects of nicotine on basal and stimulated gastric secretions in the conscious cat and in isolated guinea pig gastric mucosal cells. Agents Actions 1988 23: 289-92.

16 Cho CH, Ogle CW, Wong Sh, Lam SK. The effects of ethano and nicotine on gastrin and somatostatin release in rats. Hormone Res 1987; 25: 113-9.

$17 \mathrm{Cho} \mathrm{CH}$, Chen BW, Hui WM, Lam SK. The influence of acute or chronic nicotine treatment on ethanol-induced gastric or chronic nicotine treatment on ethanol-induced
mucosal damage in rats. $D i g$ Dis $S c i$ 1990; 35: 106-12.

mucosal damage in rats. Dig $D i s ~ S c i 1990 ; 35: 106-12$.
18 Guth PH, Leung FW. Physiology of the gastric circulation. In Johnson LR, ed. Physiology of the gastrointestinal tract. Vol 2. Johnson LR, ed. Physiology of the gastroint
New York: Raven Press, 1987: 1031-54.

19 Kivilaakso E, Fromm D, Silen W. Relationship between ulceration and intramural $\mathrm{pH}$ of gastric mucosa during hemorrhagic shock. Surgery 1978; 84: 70-7.

20 Javis LR, Whitehead R. Effect of nicotine on the morphology of the rat gastric mucosa. Gastroenterology 1978; 78 1488-94.

21 Moddy PM, Griffith RB, Averitt JH. In: Proceedings of the University of Kentucky tobacco and health research institute. Tobacco and health workshop conference. (Conference Reports Tobacco and health workshop confer
3.) Lexington, Kentucky, 1973.

22 Korman MG, Shaw RG, Hansky J, Schmidt GT, Stern AI. Influence of smoking on healing rate of duodenal ulcer in
Intermat. response to cimetidine or high dose antacid. Gastroenterology 1981; 81: 1451-3.

23 Lam SK, Hui WM, Lau WY, et al. Sucralfate overcomes adverse effect of cigarette smoking on duodenal ulcer healing and prolongs subsequent remission. Gastroenterology 1987 92: 1193-201.

24 Oates PJ, Hakkinen JP. Studies on the mechanism of ethanolinduced gastric damage in rats. Gastroenterology 1988; 94: $10-21$. 